\title{
In vitro study on biomineralization of biphasic calcium phosphate biocomposite crosslinked with hydrolysable tannins of Terminalia chebula
}

\author{
G KRITHIGA, ANTARYAMI JENA ${ }^{\dagger}$, P SELVAMANI and T P SASTRY* \\ Bioproducts Laboratory, Central Leather Research Institute, Adyar, Chennai 600 020, India \\ ${ }^{\dagger}$ Department of Pharmaceutical Technology, Anna University, Trichy 620 024, India
}

MS received 21 June 2010

\begin{abstract}
In this study, we report the preparation of a bone graft material, having cylindrical shape, containing biphasic calcium phosphate (BCP), gelatin (G), chitosan (C) and Terminalia chebula (TC) extract. TC extract was used as a crosslinker that gives stability to bone graft when it is placed in SBF. The graft was stable in the SBF solution for 21 days and FTIR, SEM, EDX and thermogravimetric studies revealed the ossification of the implant.
\end{abstract}

Keywords. Bioactive material; bone graft; biphasic calcium phosphate; crosslinking agent; biomineralization.

\section{Introduction}

Hydroxyapatite $\left(\mathrm{Ca}_{10}\left(\mathrm{PO}_{4}\right)_{6}(\mathrm{OH})_{2}\right)$ is widely explored as a bone graft material because of its similarities with the inorganic phase of bone (TenHuisen et al 1995), biocompatibility, osteoconductivity and for nonantigenic response in vivo (Suchanek and Yoshimura 1998; Fu-Yin et al 2005). It has very low biodegradability as compared to TCP which is highly resorbable (Hing et al 2007). TCP is also a potential candidate for bone graft material because of its biocompatibility and bioactivity and has the ability to form a direct bond between the tissues and the material resulting in a strong interface (Daculsi et al 1990; Langstaff et al 2001).

Recently, biphasic calcium phosphate have attracted much attention as bone graft material for repair of large bone defects, periodontal defects, orthopedic lesions and as a carrier for antibiotics in orthopedics (Jianxin et al 1998; Daculsi et al 1999). It has advantages over hydroxyapatite and TCP because of its controllable resorbability which can be adjusted by HA/TCP ratio (Simon et al 2009). The ratio 60:40 is found to be ideal for new bone formation. When tested in bone forming culture conditions HA/TCP 60:40 ratios showed high uptake of calcium when compared to other ratios. BCP has bone inductive property as early as 12 weeks in intramuscular sites when no such property is seen for hydroxyapatite and TCP when used separately (Jung-Chul et al 2009). This property is attributed to resorbability of $\mathrm{BCP}$ which involves dissolution of $\mathrm{CaP}$ crystals and then precipitation of carbonated apatite nearby the adsorbing crystals. The mineralization on their surface or inside inner spaces provides a scaffold for bone cell adhesion and further

*Author for correspondence (sastrytp@hotmail.com) bone formation (Legeros et al 2003; Daculsi and Layrolle 2004).

Chitosan, a product obtained by removal of acetyl group from chitin, is the second most abundant natural polysaccharide (Felse and Panda 1999). It is used in number of biomedical applications due to its biodegradability, nontoxicity, antibacterial activity, biocompatibility and has positive charge which acts as a binding site for other functional groups (Qi et al 2004; Shin et al 2005). In the present study, it is used along with gelatin, a degraded product of collagen which has many functional groups on its backbone, hydrophilic in nature and it favours cell attachment. Nonantigenicity and completely absorbable property of gelatin helps in preparation of wound dressing, artificial skin, and scaffold for tissue engineering and in bone grafts (Choi et al 2001; Sang et al 2003). Bone grafts were prepared by several authors using chitosan and gelatin as binders along with hydroxyapatite and $\beta$ tricalcium phosphate (Saraswathy et al 2001; Noorjahan and Sastry 2005).

In this study a fresh attempt has been made using hydrolysable tannins from Terminalia chebula (TC) extract as gelatin cross linking agent instead of glutaraldhyde to reduce the cytotoxicity (Julie et al 2002). Chemical constituents of TC extract are chebulagic acid, chebulinic acid, corilagin, beta-sitosterol, gallic acid, ellagic acid, ethyl gallate, tannic acid, galloyl glucose and chebulaginic acid (Ammar et al 2002). TC is traditionally used as antidiabetic, anti-inflammatory, laxative, antibacterial, antifungal, antiviral and antioxidant (Shivaprasad et al 2006; Mahesh et al 2009). It also helps in wound healing by increasing the concentration of collagen at wound site and by reducing the free radicals and oxidative reaction products which is encountered during wound healing (Suguna et al 2002). In the present study, a bone graft material was prepared using 
$\mathrm{BCP}$, chitosan, gelatin and extract of TC, the resultant graft material was characterized using conventional techniques.

\section{Experimental}

\subsection{Materials}

Gelatin from bovine source with bloom strength 250 was obtained from Maruthi Gel Company Ltd Trichy, India. Chitosan of $\geq 75 \%$ deacetylation was obtained from sigma Aldrich. Terminalia chebula fruits were obtained from nearby garden, Chennai, India. All other reagents were of analytical grade and used as received.

\subsection{Preparation of $B C P-C-G(I)$}

(i) Synthesis of $\beta$ TCP: $\beta$ TCP was synthesized by modifying the method of Jong et al (2004). In brief, $\left(\mathrm{CH}_{3} \mathrm{COO}\right)_{2} \mathrm{Ca} . x \mathrm{H}_{2} \mathrm{O}$ and $\mathrm{H}_{3} \mathrm{PO}_{4}$ were used as calcium and phosphorus source. Methanol was used as solvent; $7 \mathrm{ml}$ of $\mathrm{H}_{3} \mathrm{PO}_{4}$ was dissolved in methanol; subsequently $23.6 \mathrm{~g}$ $\left(\mathrm{CH}_{3} \mathrm{COO}\right)_{2} \mathrm{Ca} . x \mathrm{H}_{2} \mathrm{O}$ was added slowly along with vigorous stirring and kept for $8 \mathrm{~h}$ for precipitation. Later, the precipitate was sintered at $800 \pm 10^{\circ} \mathrm{C}$ for $5 \mathrm{~h}$ using muffle furnace. (ii) Synthesis of hydroxyapatite: Tibial bones of cattle were collected from nearby slaughter house. The bones were cut into $2 \times 2$ inch pieces using a prebeaker. Later the bone pieces were incinerated at $300^{\circ} \mathrm{C}$ and ashed at $750^{\circ} \mathrm{C}$ for about $5 \mathrm{~h}$. This treatment makes organic matter present in the bone to get volatilized and result in the formation of bone ash, which is nothing but the inorganic part of the bone and it resembles hydroxyapatite (HA) (Noorjahan and Sastry 2005). (iii) Preparation of $B C P$ : Biphasic calcium phosphate was prepared by physically mixing hydroxyapatite and $\beta$ TCP in the ratio of $60: 40$ and it is denoted as BCP. (iv) Preparation of Chitosan: $2 \mathrm{~g}$ of chitosan was dissolved in $100 \mathrm{ml} 0 \cdot 3 \mathrm{~N}$ acetic acid and it is denoted as C. (v) Preparation of gelatin: $5 \mathrm{~g}$ of gelatin was dissolved in $12 \mathrm{ml}$ of water at $50^{\circ} \mathrm{C}$ and the solution is denoted as G. (vi) Preparation of BCP-C-G bonegraft: $10 \mathrm{~g}$ of BCP, $1 \mathrm{ml}$ of $\mathrm{C}$ and $12 \mathrm{ml}$ of $\mathrm{G}$ were added and mixed well to form a dough. This dough was later extruded through glass tube $(0.8 \mathrm{~cm}$ diameter $)$ to form cylindrical-shaped implants. These implants were dried initially at room temperature $\left(30^{\circ} \mathrm{C}\right)$ for $2 \mathrm{~h}$ and later at $100^{\circ} \mathrm{C}$ for $5 \mathrm{~h}$, later cooled and stored.

\subsection{Preparation of $B C P-C-G-E(I I)$}

(i) Aqueous extract of Terminalia chebula (TC): The fruits of TC obtained were washed, air-dried and ground to fine powder. $10 \mathrm{~g}$ of this fine powder was heated in $100 \mathrm{ml}$ distilled water and heated at $60^{\circ} \mathrm{C}$ for $1 \mathrm{~h}$, filtered and the filtrate was stored at $5^{\circ} \mathrm{C}$ till further use and is denoted as $\mathrm{E}$. (ii) Preparation of BCP-C-G-E bonegraft: $5 \mathrm{~g}$ of gelatin was dissolved in $12 \mathrm{ml}$ of $\mathrm{TC}$ extract $(\mathrm{E})$ at $50^{\circ} \mathrm{C}$ and cooled. To this mixture $10 \mathrm{~g}$ of $\mathrm{BCP}, 1 \mathrm{ml}$ of $\mathrm{C}$ were added, mixed thoroughly and made into dough. This dough was extruded through a glass tube $(0.8 \mathrm{~cm}$ diameter $)$ and dried as explained above.

\subsection{Preparation of simulated body fluid $(S B F)$}

As-growth medium simulated body fluid (SBF) was used. SBF was prepared by dissolving reagent grade $\mathrm{NaCl} 7.995 \mathrm{~g}$, $\mathrm{NaHCO}_{3} 0.353 \mathrm{~g}, \mathrm{KCl} 0.224 \mathrm{~g}, \mathrm{~K}_{2} \mathrm{HPO}_{4} .3 \mathrm{H}_{2} \mathrm{O} 0.228 \mathrm{~g}$, $\mathrm{MgCl} .6 \mathrm{H}_{2} \mathrm{O} 0.305 \mathrm{~g}, \mathrm{CaCl}_{2} 0.227 \mathrm{~g}$ and $\mathrm{Na}_{2} \mathrm{SO}_{4} 0.0710 \mathrm{~g}$ in deionized water. The solution was buffered at PH7.4 with tris(hydroxylmethyl)aminomethane $\left(\left(\mathrm{CH}_{2} \mathrm{OH}\right)_{3} \mathrm{CNH}_{2}\right)$ and $1 \mathrm{M}$ hydrochloric acid $(\mathrm{HCl})$ at $36 \cdot 5 \pm 1{ }^{\circ} \mathrm{C}$ (Duan et al 2005).

\subsection{In vitro bioactivity test}

The prepared bone implants BCP-C-G (I) and BCP-C-G-E (II) were kept in $\mathrm{SBF}$ solution for 21 days at $37^{\circ} \mathrm{C}$. Later the implants were removed from the solution, washed and dried initially at room temperature and later at $100^{\circ} \mathrm{C}$. The samples were denoted as IA and IIA, respectively.

\subsection{Characterization}

To measure the compressive strength, the samples were loaded along the cylindrical axis in between the platens of the machine at a crosshead speed of $1 \mathrm{~mm} / \mathrm{min}$, using Instron 4501 model. The compressive strength was calculated from the break load and dimensions of the pellets. The IR spectra of the samples prepared were recorded in the $4000-400 \mathrm{~cm}^{-1}$ range using Nicolet Impact 400 Fourier transform infrared spectrophotometer using $\mathrm{KBr}$ pellet containing 1-2 mg of the sample. The thermo-gravimetric analysis of the samples prepared was carried out using a Seiko SSC $5200 \mathrm{H}$ in nitrogen atmosphere $(80 \mathrm{ml} / \mathrm{min})$ at a heating rate of $10^{\circ} \mathrm{C} / \mathrm{min}$. Primary weight loss of these materials as function of temperature was recorded using this study. The surface morphology was analyzed with a Topcon, SM-300 scanning electron microscope. The copper disc was pasted with carbon tape and the sample was dispersed over the tape. The disc was coated with gold in ionization chamber before microscopic analysis. E-DAX analysis was also carried out with the same instrument.

\section{Results and discussion}

\subsection{In vitro study}

Sample IA corresponding to sample I was dissolved and dispersed in SBF solution by day 5, whereas sample IIA 
corresponding to sample II was stable. Hence sample IIA was chosen for further characterization.

\subsection{Compressive strength}

Usage of synthetic crosslinking agents like formaldehyde, glutaraldhyde, EDC-NHS are being discouraged due to their cytotoxic nature. In this study, the extract of TC was used to reduce the cytotoxicity. Several authors reported the noncytotoxicity of TC extract (Ammar et al 2002; Jagetia et al 2002). TC extract is also used as a crosslinking agent in the process of preparation of leather (Sarkar 1997). Keeping this in mind the same was used as a crosslinking agent in the preparation of bone grafts in the study. Among the mechanical properties of bone repair materials, compressive strength is the most explored one. The strength of the composite depends upon various factors like particle size of individual components, nature of the additives and percentage moisture present in sample. The compressive strength of sample I, II and IIA was found to be $2.4 \mathrm{MPa}, 5.7 \mathrm{MPa}$ and 6.0 MPa, respectively. The increase in the compressive strength of sample II may be attributed to the crosslinking of the extract with gelatin and chitosan. The increase in compressive strength of sample IIA may be due to the ossification of the sample II utilizing calcium and phosphate through the SBF medium.

\subsection{FTIR}

The FTIR spectra of BCP, BCP-G-C (I), TC extract, BCP$\mathrm{G}-\mathrm{C}-\mathrm{E}$ (II) and after treatment in SBF (IIA) are shown in figure 1(a)-(e), respectively. The FTIR of BCP has shown characteristic bands for phosphate and hydroxyl groups. The $v_{1}$ and $v_{3}$ phosphate bands in 900-1200 $\mathrm{cm}^{-1}$ and $v_{4}$ absorption bands in $500-700 \mathrm{~cm}^{-1}$ spectral region were also observed in this spectrum. The band at $605 \mathrm{~cm}^{-1}$ can be assigned to the antisymmteric bending motion of phosphate groups in hydroxyapatite. The $v_{1}$ phosphate bands representing $\beta$ TCP can be seen at $942 \mathrm{~cm}^{-1}$. The $-\mathrm{OH}$ stretching bands of hydroxyl groups are seen around $3500-3700 \mathrm{~cm}^{-1}$. The FTIR spectrum of sample I exhibits amide I and II absorption bands at $1653 \mathrm{~cm}^{-1}$ and $1557 \mathrm{~cm}^{-1}$, respectively. The hydroxyl groups of chitosan are merged with those of hydroxyapatite and are seen as broad band at 1020$1100 \mathrm{~cm}^{-1}$. Figure 1(c) shows IR spectrum of the extract of

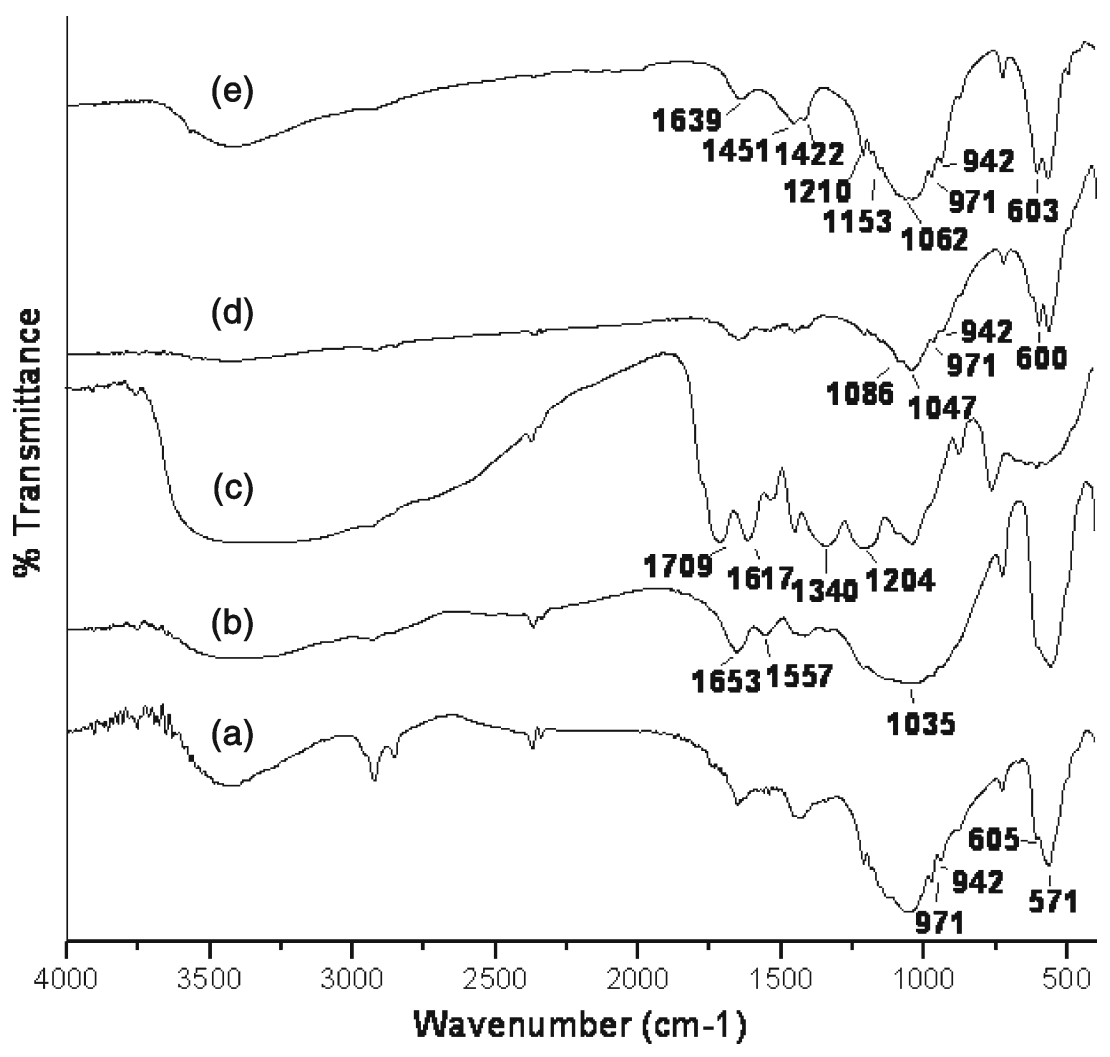

Figure 1. (a) FTIR spectrum of BCP; (b) FTIR spectrum of sample I (BCP-C-G); (c) FTIR spectrum of TC extract; (d) FTIR spectrum of sample II (BCP-C-G-E) and (e) FTIR spectrum of sample IIA (after immersion in SBF for 21 days). 

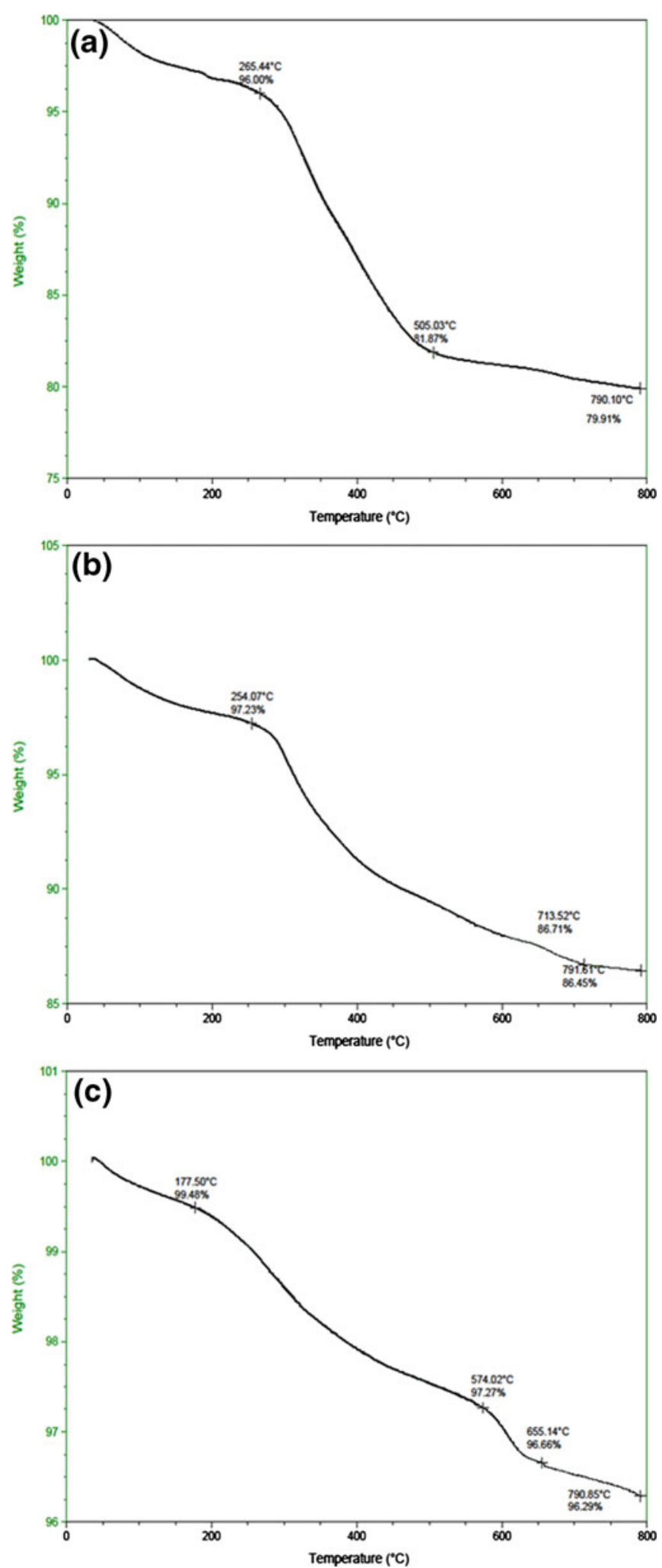

Figure 2. (a) Thermogram of sample I; (b) thermogram of sample II and (c) thermogram of sample IIA.
Terminalia chebula. It represents characteristic bands of carboxylic acids $\left(1709 \mathrm{~cm}^{-1}\right)$, amines $\left(1617 \mathrm{~cm}^{-1}\right)$ and phenols $\left(1204 \mathrm{~cm}^{-1}, 1340 \mathrm{~cm}^{-1}, 3000-3470 \mathrm{~cm}^{-1}\right)$. The FTIR spectrum of sample II shows almost disappearance of hydroxylstretching band at $3500 \mathrm{~cm}^{-1}$ and hydroxyl band at 1022$1100 \mathrm{~cm}^{-1}$ was seen with shrunken area. The intensity of amide I and II bands also reduced. This shows the functional groups of extract might have reacted with both hydroxyl and amino groups of BCP and gelatin. This data clearly shows the crosslinking between sample I and the extract. The IR spectrum of sample IIA shows reappearance of hydroxyl groups around $3400 \mathrm{~cm}^{-1}$ along with broad peak appearing around $1062 \mathrm{~cm}^{-1}$ and amide peak at $1639 \mathrm{~cm}^{-1}$. This spectrum shows BCP is intact without disintegration. It reveals the presence of carbonate apatite peaks between 1422 $1451 \mathrm{~cm}^{-1}-\mathrm{HPO}_{4}^{2-}$ groups at $1153 \mathrm{~cm}^{-1}$ and $1210 \mathrm{~cm}^{-1}$. Similar results were observed in earlier studies (Sahil et al 2006; Giuseppe et al 2008).

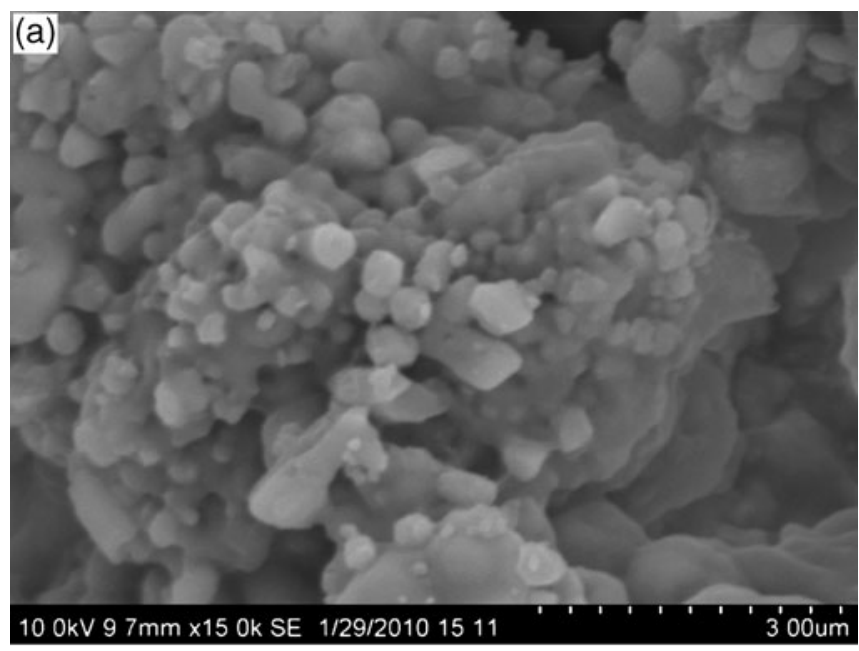

(b)

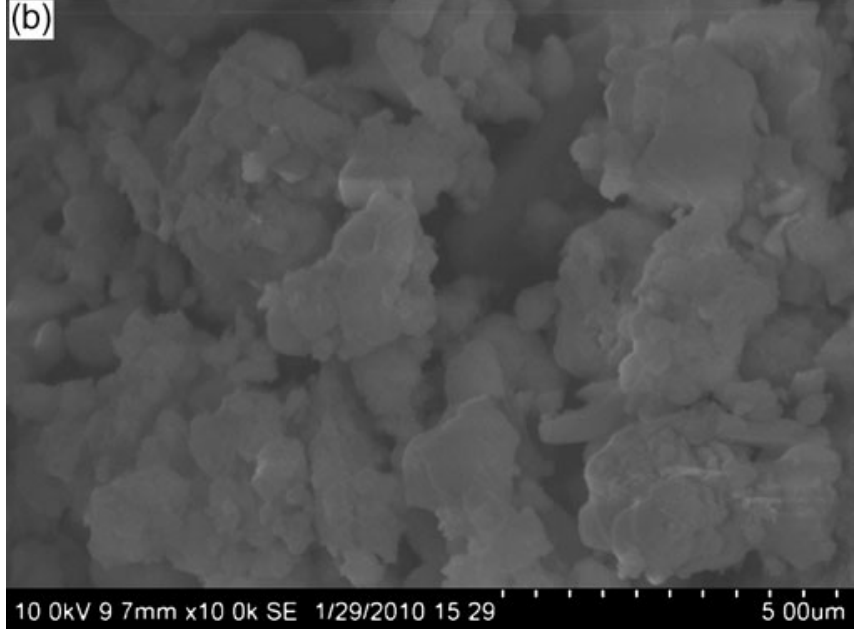

Figure 3. (a) SEM image $(\times 10 \mathrm{~K})$ of sample II demonstrating crystalline nature of $\mathrm{BCP}$ coated with gelatin and chitosan and (b) SEM image $(\times 10 \mathrm{~K})$ of sample IIA exhibiting deposition of mineral phase $\mathrm{Ca} / \mathrm{P}$ onto the sample II crystals. 

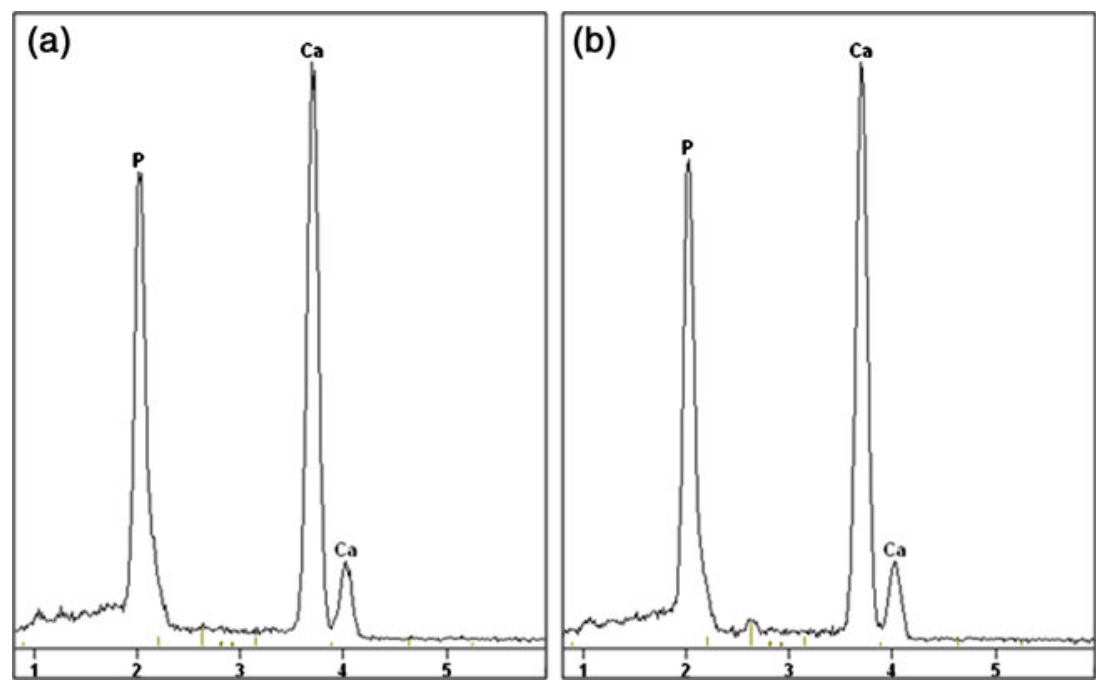

Figure 4. (a) Energy dispersive X-ray analysis of sample II and (b) energy dispersive $\mathrm{X}$-ray analysis of sample IIA.

\section{$3.4 T G A$}

Thermogravimetry reveals loss of weight of a particular substance with increasing temperature. Samples I, II and IIA were subjected to thermal analysis using TGA and their thermogram are shown in figures 2 (a)-(c). A single-step weight loss was observed between $265^{\circ} \mathrm{C}$ and $455^{\circ} \mathrm{C}$ in the case of sample I. About $80 \%$ sample I was stable at $790^{\circ} \mathrm{C}$. This weight loss may be due to decomposition of gelatin and chitosan. In the case of sample II, a two-step weight loss was observed. The first loss was observed between $240^{\circ} \mathrm{C}$ and $420^{\circ} \mathrm{C}$ by $7 \%$. The second step weight loss (4\%) was observed between $420^{\circ} \mathrm{C}$ and $714^{\circ} \mathrm{C}$, around $86 \%$ of material was stable at $790^{\circ} \mathrm{C}$. The thermal stability observed may be due to the crosslinking of gelatin and chitosan with extract. The second weight loss was also may be due to the decomposition of crosslinked gelatin and chitosan. In the case of sample IIA also the two-step weight loss was observed first being $(2 \%)$ from $157-574^{\circ} \mathrm{C}$ and second (1\%) from 574 $650^{\circ} \mathrm{C}$ and around $96 \%$ of the sample was stable at $790^{\circ} \mathrm{C}$. The increase in the thermal stability reveals the ossification of sample II; this thermal stability reveals deposition of calcium phosphate crystals onto the BCP while the sample was immersed in SBF.

\subsection{SEM}

The SEM pictures of samples II and IIA are shown in figures 3(a) and (b). Sample II shows crystalline nature of BCP coated with gelatin and chitosan. As gelatin and chitosan are coated on the BCP crystals the surface is appearing smooth, some of the crystals are seen as aggregated. The SEM picture of sample IIA clearly shows deposition of mineral phase (calcium phosphate) onto the crystals. The aggregation is seen more due to the interconnection of the crystals via calcium phosphate deposition. The SEM pictures clearly indicate the mineralization of sample II in SBF solution.

\section{$3.6 E D X$}

Figures 4(a) and 4(b) gives EDX spectra of samples II and IIA. The EDX studies have revealed the increase in calcium and phosphate contents. About $2.6 \%$ and $1.7 \%$ increase in calcium and phosphorus contents, respectively were observed in sample IIA compared to sample II, and this may be due to deposition of calcium and phosphate onto sample II and the ratio of $\mathrm{Ca}$ and $\mathrm{P}$ contents was increased by 1.52. This increase is significant for the implant in 21 days. If the implant is put in the body, this ratio may be much higher and may reach the ratio similar to that of HA (1.62), in the presence of natural physiological fluids. Based on the results obtained in this study, composites similar to sample II may be tried as osteoinductive materials using noncytotoxic plant extracts like TC as crosslinking agents.

\section{Conclusions}

In conclusion, the bone graft containing $\mathrm{BCP}, \mathrm{G}, \mathrm{C}$ and TC extract when placed in SBF was ossified. The implant also has shown better compressive strength than the sample devoid of TC. Composites similar to IIA may be tried as bone graft materials after studying their toxicological and immunological properties, in the animal models.

\section{References}

Ammar S, Michael H, Pirkko H and Kalevi P 2002 J. Ethnopharmacol. 819327 
Choi Y S, Lee S B, Hong S R, Lee Y M, Song K W and Park M H 2001 J. Mater. Sci. Mater. Med. 1267

Daculsi G and Layrolle P 2004 Key. Eng. Mater. 254-256 1005

Daculsi G, LeGeros R Z, Heughebaert M and Barbieux I 1990 Calcif. Tissue. Int. 4620

Daculsi G, Weiss P, Bouler J M, Gauthier O, Millot F and Aguado E 1999 Bone 25 59S

Duan Y R, Zhang Z R, Wang C Y, Chen J Y and Zhang X D 2005 J. Mater. Sci. Mater. Med. 16795

Felse P A and Panda T 1999 Biosystems. Bioprocess. Biosyst. Eng. 20505

Fu-Yin H, Shiao-Wen T, Chen-Wen L and Yng-Jiin W 2005 J. Mater. Sci. Mater. Med. 16341

Giuseppe F, Simona F, Barbara P and Norberto R 2008 J. Biomed. Mater. Res. A87 470

Hing K A, Wilson L F and Buckland T 2007 Spine. J. 7475

Jagetia G C, Baliga M S, Malagi K J and Sethukumar Kamath M 2002 Phytomedicine 999

Jianxin W, Weiqun C, Yubao Li, Sanjun F, Jie Weng and Xingdong Z 1998 Biomaterials 191387

Jong S B, Sz-Chian L and San-Yuan C 2004 Biomaterials 253155

Julie E G, Colin A S and Sandra D 2002 J. Biomed. Mater. Res. 61 121

Jung-Chul P, Hyun-Chang L, Joo-Yeon S, Jeong-Ho Y, Ui-Won J, Chang-Sung K, Kyoo-Sung C, Chong-Kwan K and Seong-Ho C 2009 J. Korean. Acad. Periodontol. 39223

Langstaff S D, Sayer M, Smith T J N and Pugh S M 2001 Biomaterials 22135
Legeros R Z, Lin R, Rohanizadeh D, Mijares D and Legeros J P 2003 J. Mater. Sci. Mater. Med. 14201

Mahesh R, Bhuvana S and Hazeena Begum V 2009 Cell. Biochem. Funct. 27358

Noorjahan S E and Sastry T P 2005 J. Biomed. Mater. Res. B75 343

Qi L X Z, Jiang X, Hu C and Zou X 2004 Carbohydr. Res. 339 2693

Sahil J, Sarit B, Bhaduri A and Cuneyt T 2006 J. Biomed. Mater. Res. A78 481

Sang B L, Hyun W J, Young W L, Kang W S, Moon H P, Young S N and Hee C A 2003 Biomaterials 242503

Saraswathy G, Pal S, Rose C and Sastry T P 2001 Bull. Mater. Sci. 24415

Sarkar K T 1997 Theory and practice of leather manufacture. (Chennai: The Author) p. 309

Shin S Y, Park H N, Kim K H, Lee M H, Choi Y S, Park Y J, Lee Y M, Ku Y, Rhyu I C, Han S B, Lee S J and Chung C P 2005 J. Periodontal. 761778

Shivaprasad H N, Kharya M D, Rana A C and Mohan S 2006 Pharm. Biol. 4432

Simon S J, Michael M B, Michel D, Dieter D B and Daniel B 2009 J. Biomed. Mater. Res. Part B: Appl. Biomater. B90 171

Suchanek W and Yoshimura M 1998 J. Mater. Res. 1394

Suguna L, Surjeet S, Sivakumar P, Padmavathi S and Gowri C 2002 Phytother. Res. 16227

TenHuisen K S, Martin R I, Klimkiewiez M and Brown P 1995 Biomed. Mater. Res. 29803 